\title{
THE MECHANISM OF ECONOMIC MANAGEMENT IN THE REGIONS OF KAZAKHSTAN TO ENSURE ENVIRONMENTAL SAFETY
}

\author{
Laura Igaliyeva ${ }^{1}$, Saule Yegemberdiyeva ${ }^{2}$
}

\begin{abstract}
This article describes the objectives and methods of ecological environment management and sustainable environmental management at the regional level and with the impact of economic instruments. The optimum solutions to environmental management problems with a view to preserving natural resources and the reduction of risk of harm to the ecological environment were examined. Based on the analysis of conceptual approaches to the formation of the economic mechanism for ensuring environmental safety, the fundamental principles of the formation of this mechanism in Kazakhstan have been determined. On the basis of scientific research, measures are proposed for the effective operation of the economic mechanism of environmental management in Kazakhstan, which ensures the competitiveness of national products in the domestic and foreign markets, overall economic stability and national welfare in general.
\end{abstract}

JEL Classification Numbers: Q5, Q50, DOI: 10.12955/cbup.v7.1353

Keywords: ecological safety, Economic indicators, national safety, guard of environment

\section{Introduction}

The formation of methodical bases of development of the regional ecological management providing effective functioning of economy of the region and its subjects - the enterprises in modern conditions of managing is complicated by an insufficiency of the analysis of economic and administrative problems of ensuring ecological safety. Thus, in the management of economic activities of the total set of economic indicators are not identified environmental indicators. This often leads to non-fulfillment of potentially possible environmental and economic measures and to a decrease in income in enterprises. The solution of environmental and economic problems at the enterprise is allocated from zero to hundredths and tenths of a percent of profit, while in the budget of the region is-less than $0.5 \%$ of all expenses.

Currently, Kazakhstan does not have a single strategy to ensure the development of economic activity taking into account market conditions and environmental safety requirements in the region, the management accounting of environmental and economic activities is not carried out, the existing structure of environmental and economic management is ineffective, and business planning in this area is not carried out. Most enterprises do not realize the need for environmental management, environmental marketing, environmental audit, environmental impact assessment and other organizational and economic mechanisms (Sikhimbayev and Khanov, 2014).

The development of management and economic activities of the region and its enterprises is constrained by the lack of development of theoretical issues, methodological and regulatory framework. To manage the economy of the region taking into account environmental safety, it is necessary to develop strategic plans and sustainable development programs (Golichenkov, 2001).

The purpose of the study is to substantiate the formation and development of the main functional components of the integrated economic mechanism to ensure environmental safety of Kazakhstan.

\section{Data and Methodology}

The goal of this research is to justify the development of the main functional components of an integrated economic mechanism for ensuring the environmental safety of Kazakhstan.

In the course of the research, methods of analysis and compilation were used to achieve the objectives. The methods of environmental research in the region have been analyzed by means of observations and surveys. Comparative table-based comparisons of general official statistical data were conducted.

\section{Results and Discussion}

The Republic of Kazakhstan is one of the countries in the world with the most difficult environmental situation. The current state of the environment is a consequence of decades of extensive policy approach to the development of productive forces and the exploitation of natural resources, ignoring regional environmental problems. The transformation of Kazakhstan's economy on market principles with the strengthening of raw materials orientation without due consideration of environmental

\footnotetext{
${ }^{1}$ L.N. Gumilyov Eurasian National University, Astana, Kazakhstan, igalieva82@mail.ru
}

${ }^{2}$ L.N. Gumilyov Eurasian National University, Astana, Kazakhstan, saule_8@mail.ru 
restrictions has led to an even greater aggravation of the environmental situation, in which the degradation of the natural environment has reached a catastrophic level, which poses a threat to the national security of the Republic of Kazakhstan (Smoilov, 2005). Therefore, the problem of formation of the system of environmental interests and hierarchy of social values on a natural and historical basis and, accordingly, the priority of developing an environmentally sound development strategy of the Republic of Kazakhstan and the formation of an economic mechanism that reflects the requirements of environmental safety is key. In this regard, the use of the principles and provisions of the concept of sustainable development, recognized by the world community as the basic ideology of economic, social and environmental balance of society, is particularly relevant for the Republic of Kazakhstan (Soltanbekova, 2009).

The experience of recent decades shows an increase in the number of natural and man-made disasters with serious environmental and socio-economic consequences. A prerequisite for the occurrence of disasters are environmental risks associated with the presence of dangerous natural and anthropogenic factors. The identification of the main environmental risks affecting the economy of Kazakhstan makes it possible to develop and implement more effective state policy in the field of greening the economy, production, development of environmental technologies, especially in leading industries. This is also relevant because the Republic, implementing the "Strategy 2050", "The Concept of transition to sustainable development for 2007-2024" aims at a long-term environmental strategy involving involving the harmonization of interaction between society and the environment, as well as the creation of an environmentally safe, favorable habitat. Implementing the strategic objectives of the concept through increasing the efficiency of resource use, increasing life expectancy, providing an increase in the index of environmental sustainability, will create an opportunity for Kazakhstan to be on the level of quality of life among the most competitive and developed countries of the world (Baimbetov and Idirisova, 2012).

According to the published monitoring on the state of the environment in the Republic of Kazakhstan, prepared by a group of Kazakh and Russian scientists and experts of UNDP in Kazakhstan, Kazakhstan can be declared a zone of environmental disaster. It is estimated that 75 per cent of the country is at increased risk of environmental destabilization (Bezvidnaya, 2013).

About 5 million people in Kazakhstan live in polluted air, and 2 million live in extremely high levels of pollution.

In 2017, stationary sources of enterprises and individual entrepreneurs of the country released 2357.8 thousand tons of pollutants into the air, which is $3.7 \%$ more than in 2016. Treatment facilities of stationary sources captured and neutralized $92.3 \%$ of the total amount of pollutants received.

The largest volumes of emissions of the main types of specific pollutants are : sulfur dioxide - 786.4 thousand tons, carbon monoxide - 431.9 thousand tons and nitrogen oxides -264.7 thousand tons.

The main emissions of pollutants into the air were carried out by industrial enterprises, which account for $84.1 \%$ of all emissions.

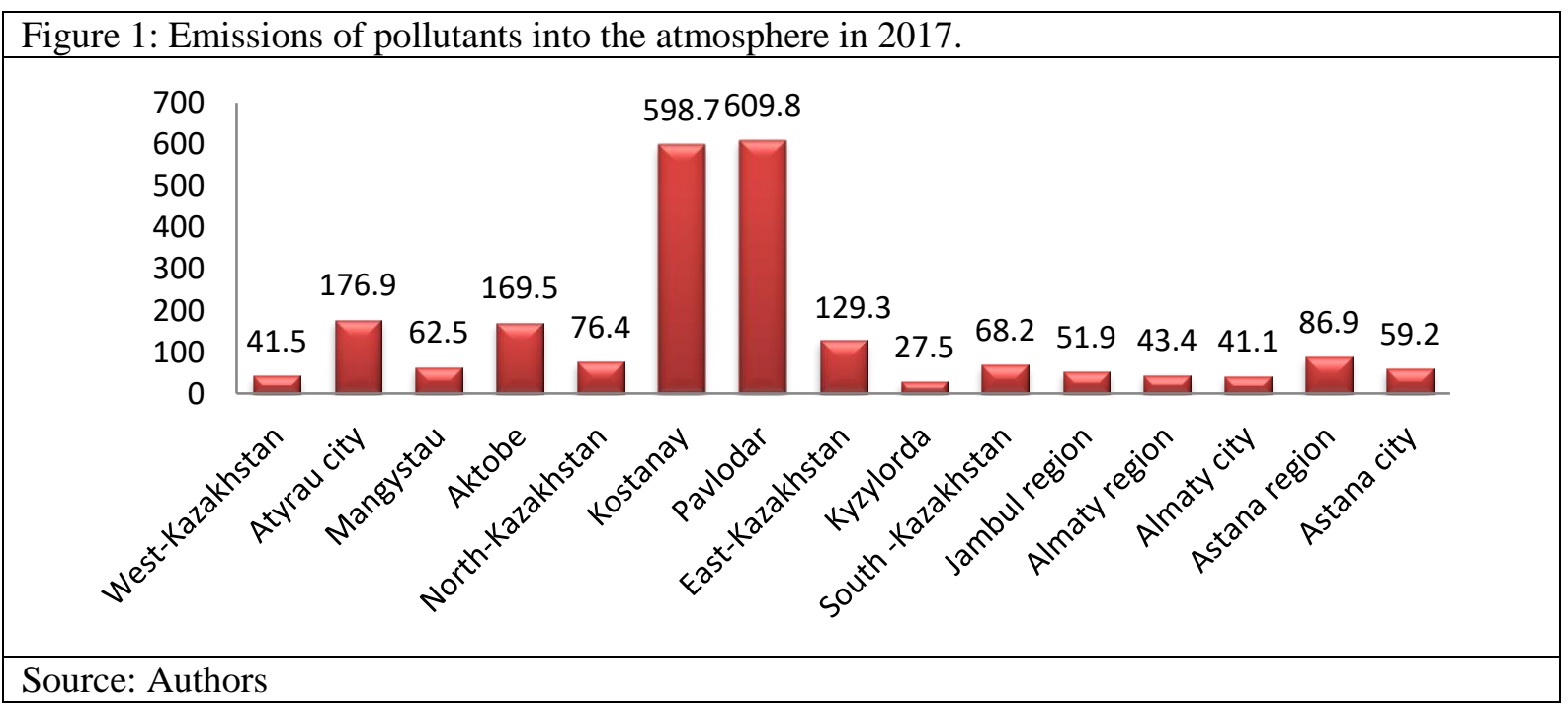


The need for transition to sustainable economic development is due to a number of factors:

First, there is inefficient use of resources in all major sectors of the economy. According to experts, this leads to a loss of profit of 4-8 billion USD per year for the economy, and by 2030 could reach up to 14 billion USD.

Secondly, there is a deterioration in the quality of land due to the natural processes of desertification, erosion, as well as due to anthropogenic factors (pollution, contamination, irrational use).

Thirdly, there is a problem of rational use and protection of waters of the Republic of Kazakhstan. Water bodies of Kazakhstan are heavily polluted by enterprises of mining, metallurgical and chemical industries, and municipal services of cities, and pose a real environmental threat. Groundwater, which is the main source of drinking water for the population, is also subject to pollution.

Fourth, the level of air pollution remains high. There is a high level of air pollution in the cities, the level of concentration of solid particles is ten times higher than in the European Union. Air pollution is estimated to cause up to 6,000 premature deaths per year.

Fifth, there is the problem of disposal of production and consumption waste. Especially the production activities of the oil and gas industry in many cases does not meet the requirements of environmental safety. There is no integrated waste management system. $97 \%$ of municipal solid waste is disposed of in uncontrolled landfills and landfills that do not meet sanitary standards. Also a serious problem is the historical toxic and radioactive waste of the industry.

And this is not the whole list of environmental problems of Kazakhstan. It is established that environmental factors are directly related to human activity. According to the Committee of experts of the world health organization (WHO), 95\% of all pathologies are directly or indirectly related to the adverse environment.

Thus, $90 \%$ of all cancer cases are caused by the negative impact of environmental factors. Of these, $80 \%$ of cases are associated with exposure to chemical carcinogens and about $10 \%$ - radiation (Gergova, 2007).

An analytical review of the current state of ecology in Kazakhstan has revealed a number of problems presented in Table 2 below.

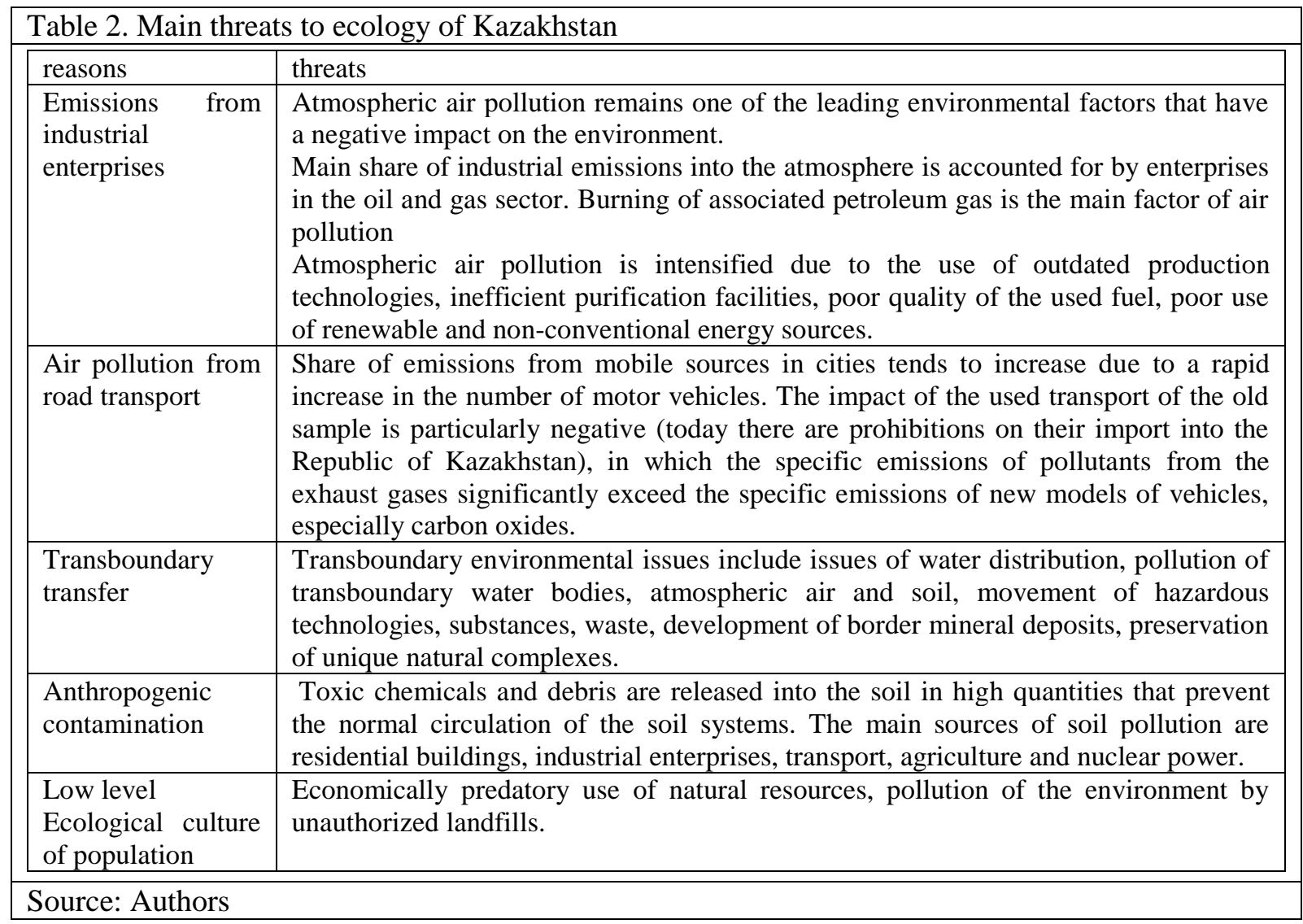


Air pollution surveys were conducted in 19 cities of the country. The highest level of pollution has been noted in 10 cities ( 8 of which had a high level of air pollution), for example, Almaty, Ridder, Shymkent, Ust-Kamenogorsk, Karaganda, etc. Sometimes the maximum concentrations of pollutants exceed MPC by 10-20 times (for example, in Balkhash and Ust-Kamenogorsk for sulfur dioxide).

Developing of the economic mechanism for the country's environmental safety during the transition to market relations has become an organic integral system of economy management and regulation.

A special role is imposed on the system of economic standards and legal norms of enforcement actions on natural resource consumers, forming the basis of the economic mechanism in ensuring environmental safety. The essence of this mechanism is realized through the basic principle of rational nature management when the polluters and the users of natural resources bear the main costs of restoring disturbed natural integrity, as well as the introduction of environmentally friendly technologies and materials (Aidosov et al., 2018).

To implement the regulation of environmental safety of Kazakhstan it is necessary to create an effective set of economic mechanism (Figure 2).
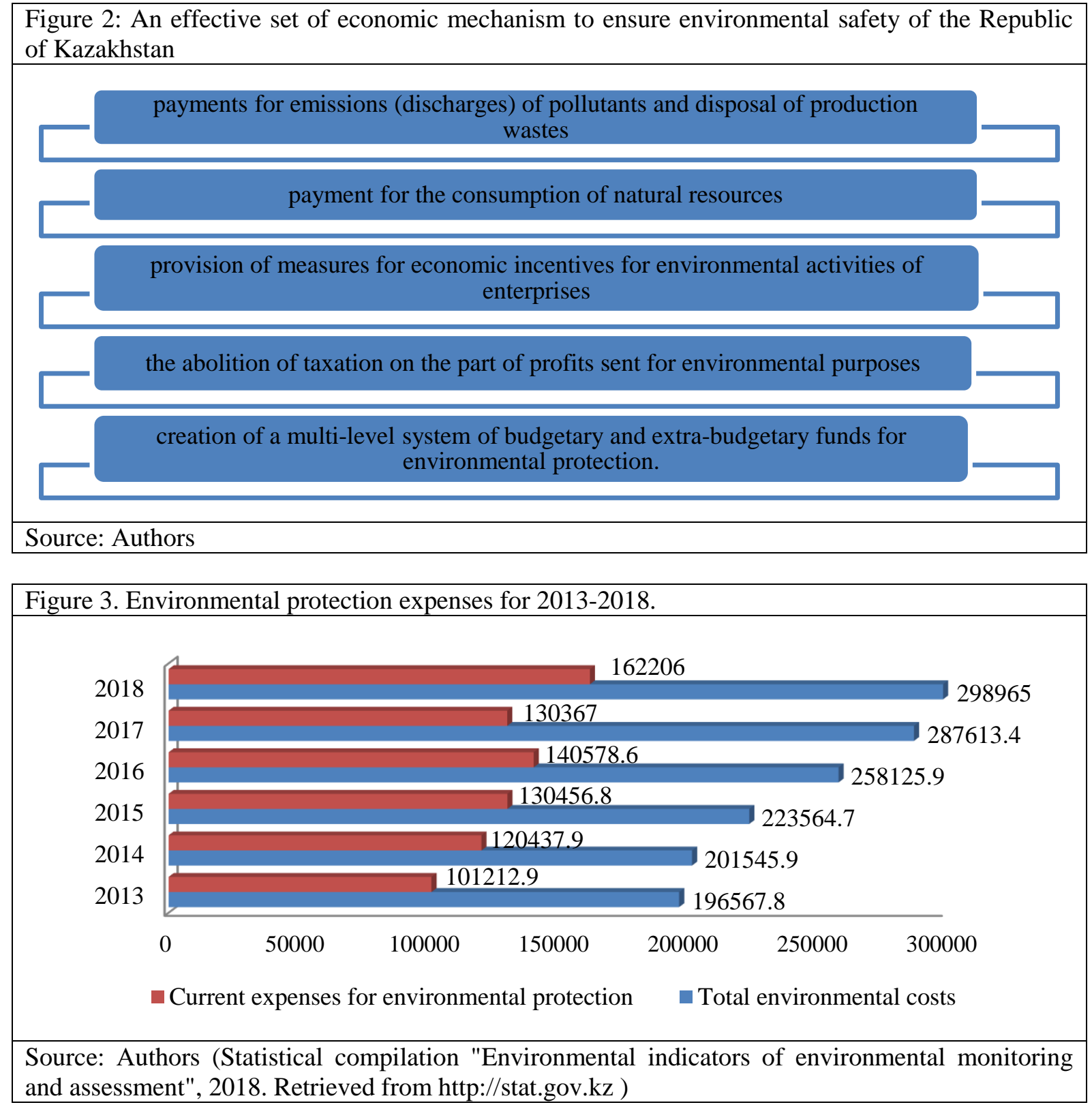

This economic mechanism calls for regulating the use of natural resources on a regular basis, without violating environmental legislation, through limit and over-limit payments. 
It seems reasonable to also add an exemption from value added tax and profit reserves, for national and arboretum parks and Botanical gardens. This would significantly improve the financial situation of the reserves. It would also be possible to reduce the tax base of enterprises by the amount of funds from their own sources of financing aimed at capital investments that reduce emissions, discharges of harmful substances when calculating the tax on the income of legal entities. Given the current tight financial and tax policies, the company gets the opportunity to finance environmental protection at its own expense. (Kussainov et al., 2015).

The state allocates a lot of funds for programs for the protection of the environment, soil, water, etc., but they often do not reach their destination. Science is also looking for ways to overcome environmental risks, for example, domestic scientists are now conducting research on the purification of soils contaminated with oil, and offer very simple and economical ways, with the help of microbes, the vegetation of the same soil.

As can be assumed from the analysis, Kazakhstan is systematically strengthening environmental safety. This activity finds a well-deserved assessment of the world community. As a result of state initiatives, Kazakhstan was the first of the countries of the Central Asian sector to be elected a nonpermanent member of the UN Security Council. Kazakhstan conducts environmental propaganda and develops environmental education.

Ecology problems all over the world are not local, no single country can solve them. And the solution of the most pressing issues of the state of ecology in Kazakhstan does not depend only on its efforts. Ecological safety acts as a basic value of modern society, and in this respect, the dominant influence of policies expressing social values and implementing measures aimed at shaping and protecting these values is manifested.

\section{Conclusion}

Global environmental problems undoubtedly affect and will affect the health of the population of the Republic, the nature of environmental management and industrial infrastructure. Unfortunately, it should be noted that in the Republic of Kazakhstan very little influence is given to the issues of adaptive measures to global environmental problems. This can be explained by the lack of coverage of this issue among decision makers and the fact that environmental activities have not been a priority for the country's development for a long time.

Unsolved environmental problems significantly affect the health and life of citizens of the Republic of Kazakhstan. The Concept for the transition of the Republic of Kazakhstan to a "green" economy states that "environmental pollution has a serious negative impact on human health. According to international studies, about 40,000 children under the age of 10 have neurological disorders as a result of excessive exposure to lead. Kazakhstan is the second largest country in Central and Eastern Europe and Central Asia in terms of total pollution of the environment with organic substances."

This indicates that the Republic of Kazakhstan has not yet established proper regulation of environmental protection, which leads to serious financial losses. Thus, "the lost profit from the inefficient management of natural resources can reach up to 7 billion USD by 2030".

This problem requires a fairly deep and comprehensive analysis, which necessitates theoretical development and the formation of proposals and recommendations for the development of the most effective financial policy in this area, the optimal economic mechanism for environmental protection and environmental management.

The current mechanism of economic management of environmental protection and nature management is not a single picture, it consists of separate and not always interrelated elements.

This state of Affairs is largely due to the shortcomings in the formation of environmental policy, strategy and programs of Kazakhstan and the absence to date of a structured and formalized system of indicators for setting goals in the field of environmental safety and assessment of their achievement (Harris et al., 2017).

In order to create conditions for sustainable development of the region, as well as environmental safety, the priority is to develop and implement a regional economic mechanism. For sustainable environmental management at the regional level using economic instruments of environmental impact 
we offer methods of management of the economic mechanism in ensuring environmental safety of regions of the Kazakhstan.

1. Reduction in negative technogenic impact on the environment

2. Efficiency of proper disposal of industrial waste

3. Planning and financing of environmental programs.

4. Improvement of organizational and economic mechanism of greening

5. Formation of market infrastructure of environmental safety.

6. Ensuring the improvement of the environmental management system in the field of environmental protection and environmental management.

7. Introduction of innovative developments in environmental activities

To develop mechanisms for sustainable management of environmental quality and environmental management, it is necessary to ensure the functioning and further development of the unified state system for monitoring the environment and natural resources, the foundations of which are reflected in the Environmental code of the Republic of Kazakhstan.

The increased attention of the state to the issues of environmental safety and the consolidation of a set of measures for the economic stimulation of environmental activities will create a reliable basis for the stability of economic development and the protection of the health of the population and future generations.

\section{References}

Aidosov A., Aidosov G. A., Zaurbekov N. S. (2018). Theoretical and methodological bases for the regulation of environmental safety. // Monograph. Almaty. pp 45-52.

Baimbetov N., Idirisova B. (2012). Security Ecology Of Kazakhstan Journal: Bulletin of the treasury. Almaty.pp 115-117.

Bezvidnaya M. (2013). Environmental cost management issues. The mechanism for ensuring environmental safety: Russian and foreign experience. Proceedings of the international scientific conference. P-65.

Conception on the conservation and sustainable use of biological diversity of the Republic of Kazakhstan until 2030.//Astana, 2015

Environmental Code of the Republic of Kazakhstan dated January 9, 2007 / PARAGRAPH Information System

Gergova Z. (2007). The economic security mechanism in the region's economy. Economics and efficiency of organization of production: a collection of scientific papers on the basis of the international scientific and technical conference / Z. $\mathrm{H}$. Gergovo. - Bryansk: BGITA, Issue 8. - 286 p.

Golichenkov A.K. (2001). Environmental protection, ensuring environmental safety, ensuring the rational use of natural resources: the general and the particular // Environmental safety: problems, search, solutions. pp. 141-146.41

Harris J. M., Roach B., Codur A. M..(2017). The Economics of Global Climate Change. // Global Development and Environment Institute, Tufts University. pp. 120-122

Kussainov T. A., Maitah M., Kurmanov N. A., Hájek P., Tolysbaev B. S., Baidakov A. K. (2015). Economic Analysis of the Impact of Changing Production Conditions on Wheat Productivity Level. Review of European studies// Canadian Center of Science and Education. 7(11), p. 125.

Sikhimbayev M., Khanov T. (2014). Ways of ensuring environmental safety in oil-producing regions of Kazakhstan // International Journal of Applied and Fundamental Research. № 8-1. pp. 101-105.

Smoilov S.(2005). Problems of legal support of the mechanism of economic regulation of environmental protection and environmental management in the Republic of Kazakhstan, Almaty. pp 33-41.

Soltanbekova B. (2009). Improving the economic mechanism environmental protection in the Republic of Kazakhstan.pp 123-135.

Statistical compilation "Environmental indicators of environmental monitoring and assessment" // Astana, 2018.

http://stat.gov.kz 